\title{
Pattern of Dermatological Diseases in the Patients of Army Hospital, Kathmandu
}

\author{
Jha $\mathrm{SM}^{1}$, Rajbhandari $\mathrm{SL}^{2}$, Shakya $\mathrm{N}^{3}$, Pokharel $\mathrm{A}^{4}$, Jha $\mathrm{B}^{5}$
}

${ }^{1}$ Dr. Sagar Mani Jha, Dermato-venereologist, ${ }^{2}$ Dr. Sudarsan Lal Rajbhandari, Professor, ${ }^{3}$ Dr. Nabinbhakta Shakya, Dermato-venereologist, ${ }^{4} \mathrm{Dr}$. Arbind Pokharel, Dermato-venereologist, Department of Dermatology and Sexually transmitted Disease, Shree Birendra Hospital, Chhauni, ${ }^{5}$ Dr. Beena Jha, General Practice, Kathmandu, Nepal.

\begin{abstract}
Introduction: Human Skin is the largest organ of the body and may mirror the presence of benign/ malignant systemic diseases in different ways ${ }^{1}$. The pattern of Skin diseases vary in different parts of Nepal due to differences in socioeconomic and geographic factors. This retrospective study, pattern of skin disease in Army Hospital likely reflects the pattern of disease in the Kathmandu Valley.

Aim: To study, assess and compare the different patterns of skin disease in the patients attending the outpatient department in the year 2007 and 2008 in the Army Hospital.

Methods: This was a retrospective study and all the new cases which were diagnosed in the Department of Dermatology in the years 2007 and 2008 were included. The diseases were classified as Papulosquamous, Vesicobullous, Connectivetissue disorders, Skin and Soft tissue tumours, Infective, Eczema, Sexually Transmitted Disease (STI), Leprosy and those skin diseases which were not coming under this format were classified as others.

Result: The total number of cases recorded in the Department of Dermatology were16828 in the year 2007 and 18643 in 2008. It was found that the infective group of disorders were the largest group of disease, in the year 2007 a total of $6135(36.4 \%)$ and in 2008 a total of 7883(42.2\%) had suffered from this group of disorders. And the incidence of infective disorder was also statistically significant when both the years were compared p-Value:0.00, OR:1.16, Cl:1.11-1.21. Similarly other large groups were Eczema, papulosqumous and sexually tranmitted disease.

Conclusion: It was found that the disease pattern in this study was lead by infective disease followed by eczema, papulosquamous disease and sexually transmitted disease.
\end{abstract}

Key words: Eczema, Papulosquamous, Vesicobullous

\section{Introduction}

Human Skin is the largest organ of the body and may mirror the presence of benign/malignant systemic diseases in different ways ${ }^{1}$. The pattern of Skin diseases vary in different parts of Nepal due to differences in socioeconomic and geographic factors. The army hospital in Kathmandu not only treats regular personnals but also their family and ex- servicemen who comprise almost $60 \%$ of the population who get their treatment. This retrospective study, pattern of skin disease in Army
Hospital, likely reflects the pattern of disease in the Kathmandu Valley.

\footnotetext{
Aim

To study, assess and compare the different patterns of skin disease in the patients attending the outpatient department in the year 2007 and 2008 in the Army Hospital.
} 


\section{Methods}

This was a retrospective study and all the new cases which were diagnosed in the Department of Dermatology in the years 2007 and 2008 were included. In this study males and females of all age group were included. The diseases were classified as Papulosquamous, Vesicobullous, Connectivetissue disorders (CTD), Skin and Soft tissue tumours, Infective, Eczema, Pigmentary Disorders, Sexually Transmitted Disease (STI), Leprosy and those skin diseases which were not coming under this format were classified as others. Data was tabulated and interpreted in terms of percentage in the computer using SPSS version 10.0. To test the significance of association Chi square test was applied.

\section{Results}

The total number of cases recorded in the Department of Dermatology were16828 in the year 2007 and 18643 in 2008 . The number and percentages of the skin diseases are given in Table 1.

In the papulosquamous group the incidence of psoriasis was highest in both the years, 1544(44.8\%) in 2007 and 1437 (38.0\%) in 2008. A total of 437(2.5\%) in the year 2007 as compared to 336(1.8\%) in 2008 suffered from vesicobullous condition and it was statistically significant p-Value 0.00, Odds Ratio(OR):0.69, Confidence Interval (Cl):0.60-0.80. Pemphigus vulgaris was the most common condition in both the years.

The incidence of Systemic Lupus Erythematosus was highest in both the years in the connective tissue group. But when both the years were compared the incidence of CTD was statistically significant ( $p$ Value.0.003, OR:0.71, Cl:0.57-0.90). Most of the skin and soft tissue tumours were benign in nature. Among infective disorders, dermatophytosis 3463 (56.4\%) occurred in maximum number of patients. And the incidence of infective disorder was also statistically significant when both the years were compared $\mathrm{p}$ Value:0.00, OR:1.16, Cl:1.11-1.21. The incidence of Seborrhic Dermatitis $780(19.4 \%)$ and $810(19.5 \%)$ followed by Airbourne contact dermatitis 631(15.7\%) and 745(17.9\%) in the year 2007 and 2008 respectively was noted. The eczematous conditions were also statistically significant in both the years ( $p$-Value:0.005, OR:0.93, $\mathrm{Cl}: 0.89-0.98)$. The incidence of vitiligo and melasma was highest in the pigmentary disorder group. The incidence of pigmentary disorder was statistically significant when both the years were compared p-Value:0.00, OR:0.75, $\mathrm{Cl}: 0.69-0.81$. Gonococcal urethritis was most common $\mathrm{STI}$ in both the years. And incidence of STIs were significant when compared between the incidence of 2007 as compared to 2008 (p- Value:0.00, OR: 0.75, $\mathrm{Cl}: 0.69-0.81)$. The incidence of leprosy was comparable in both the years. In the other disease category various conditions were included and the main disease were Neurofibromatosis 6, Tuberous sclerosis 2, various types of naevi 60, Portwine stain16, Alopecia Areata 57, different types of Photodermatoses 469, drug reactions 120 in both the years.

Table 1: Number and percentages of the skin diseases

\begin{tabular}{|l|c|c|c|c|}
\hline \multirow{2}{*}{ Dermatoses } & \multicolumn{2}{|c|}{ Total(N):16828 } & \multicolumn{2}{c|}{$\begin{array}{c}2008 \\
\text { Total(N):18643 }\end{array}$} \\
\hline Papulosquamous & 3446 & $20.4 \%$ & 3779 & $20.2 \%$ \\
\hline Vesicobullous, & 437 & $2.5 \%$ & 336 & $1.8 \%$ \\
\hline Connective tissue disorders & 168 & $0.9 \%$ & 133 & $0.7 \%$ \\
\hline Skin and Soft tissue tumours & 39 & $0.2 \%$ & 35 & $0.1 \%$ \\
\hline Infective & 6135 & $36.4 \%$ & 7883 & $42.2 \%$ \\
\hline Eczema & 4008 & $23.8 \%$ & 4147 & $22.4 \%$ \\
\hline Pigmentary Disorders & 376 & $2.2 \%$ & 299 & $1.2 \%$ \\
\hline Sexually Transmitted Disease & 1467 & $8.7 \%$ & 1214 & $6.5 \%$ \\
\hline Leprosy & 24 & $0.1 \%$ & 17 & $0.09 \%$ \\
\hline Others & 728 & $4.3 \%$ & 800 & $4.2 \%$ \\
\hline
\end{tabular}




\section{Discussion}

In this study various pattern of dermatological disease were studied in the outpatient department of the army hospital in Kathmandu. Various socioeconomic and geographical conditions are responsible for different pattern of disease. Moisture, temperature, hygine, food habits, medications, sexual exposure, lower immunity are some of the causes of various disease.

In our study infective conditions were very high. The highest being dermatophyte infections. Low socioeconomic conditions, high humidity and working condition are factors which influence the increase in incidence ${ }^{1}$. Similar results have been recorded in a study conducted in Delhi ${ }^{2}$. The condition increased from 36.4\% in 2007 to $42.2 \%$ in 2008 which was a significant increase ( $p$-Value 0.00 ). The other group of diseases were various types of eczema and papulosquamous disease. Eczema was the second largest group of skin diseases. Airbourne contact dermatitis was very common in this part of our country. Most of the people of Nepal are cultivators and are engaged in fields. As such they come in contact with different sensitizers and detergents ${ }^{1}$. In a general practice in Belfast, $8 \%$ of patients seen during an 8week period had a dermatological condition. Dermatitis or eczema accounted for $25 \%$ of these, of which $63 \%$ were considered to be exogenous in origin ${ }^{3}$.

The other large group was that of Sexually Transmitted infections. Gonococcal urethritis was the condition which was suffered by maximum patients attending the clinic. The higher incidence of STI can be attributed to lack of knowledge about barrier contraceptives. There was significant statistical difference in the incidence of STIs in the year 2007 and 2008, p-Value:0.00. Similarly there was also significant difference in vesicobullous and pigmentary disorders in 2007 and 2008. Pemphigus vulgaris was the most common vesicobullous disorder among patients attending our out patient department. Pemphigus vulgaris accounts for approximately $70 \%$ of all cases of pemphigus and may be the most common autoimmune blistering disease in eastern countries, such as India, Malaysia, China and the Middle East ${ }^{4,5}$. The incidence of leprosy was comparable in both the years. Most of the skin and soft tissue tumours were benign in our study. The incidence of photodermatoses especially polymorphic light eruption(PLE) was also found to be high. PLE is most common in temperate regions, affecting up to $20 \%$ of subjects in such areas ${ }^{6,7}$.

\section{Conclusion}

Infective skin disorders, Eczema, Papulosquamous disorders and STIs were most common pattern of dermatological condition found in this hospital. The pattern found in our study was in general similar to that found in various other studies in this subcontinent.

\section{Acknowledgment}

It gives me great pleasure to express my deep sense of gratitude to my highly respectable teachers Prof Sudha Agrawal and Dr Tapan Kumar Dhali for their excellent and able guidance in performing this study. Similarly I am grateful to the staff of Department of Dermatology and STI and staff of the record section of Shree Birendra Hospital for their cooperation.

\section{Conflict of interest: None}

Fundings: None

\section{References}

1. Das KK. Pattern of dermatological diseases in gauhati medical college and hospital Guwahati. Indian J Dermatol Venereol Leprol 2003;69:16-8

2. Karanti Bhala K. Pattern of skin diseases in a semi urban community of Delhi. Indian J Dermatol Venereol Leprol 1984;50:213-214.

3. Steele K. Primary dermatological care in general practice. JR Coll Gen Pract 1984; 34: 22-4.

4. Wilson C, Wojnarowska F, Mehra NK et al. Pemphigus in Oxford, UK, and New Delhi, India: a comparative study of disease characteristics and HLA antigens. Dermatology 1994; 189 (Suppl. 1): 108-10.

5. Adam BA. Bullous diseases in Malaysia: epidemiology and natural history. Int $\mathrm{J}$ Dermatol 1992; 31: 42-5.

6. Morison WL, Stern RS. Polymorphous light eruption: a common reaction uncommonly recognized. Acta Derm Venereol (Stockh) 1982; 62: 237-40.

7. Pao C, Norris PG, Corbett M, Hawk JLM. Polymorphic light eruption: prevalence in Australia and England. Br J Dermatol 1994; 130: 62-4. 